\title{
Emergent modeling: discrete graphs to support the understanding of change and velocity
}

\author{
L. M. Doorman · K. P. E. Gravemeijer
}

Accepted: 18 July 2008/Published online: 16 September 2008

(c) The Author(s) 2008. This article is published with open access at Springerlink.com

\begin{abstract}
In this paper we focus on an instructional sequence that aims at supporting students in their learning of the basic principles of rate of change and velocity. The conjectured process of teaching and learning is supposed to ensure that the mathematical and physical concepts will be rooted in students' understanding of everyday-life situations. Students' inventions are supported by carefully planned activities and tools that fit their reasoning. The central design heuristic of the instructional sequence is emergent modeling. We created an educational setting in three tenth grade classrooms to investigate students' learning with this sequence. The design research is carried out in order to contribute to a local instruction theory on calculus. Classroom events and computer activities are video-taped, group work is audio-taped and student materials are collected. Qualitative analyses show that with the emergent modeling approach, the basic principles of calculus can be developed from students' reasoning on motion, when they are supported by discrete graphs.
\end{abstract}

L. M. Doorman $(\square)$

Freudenthal Institute for Science and Mathematics Education, Utrecht University, Postbus 9432,

3506 GK Utrecht, The Netherlands

e-mail: m.doorman@fi.uu.nl

K. P. E. Gravemeijer

Eindhoven School of Education,

Eindhoven University of Technology,

Postbus 513, 5600 MB Eindhoven, The Netherlands

\section{Introduction}

The content of the instructional sequence in this report is calculus and kinematics. Historically, these two topics originated from observing and organizing motion phenomena. Historical knowledge of how we might symbolize motion is used to understand how the related graphs and concepts were invented, and to obtain clues for an integrated approach of calculus and kinematics. Especially for mathematics education, we need to apply such knowledge to prevent students from acquiring an instrumental use of mathematical symbols without understanding the represented concepts.

Since the 1970s graphs play an important role in the teaching of calculus and kinematics. Often, distance-time graphs are used to give meaning to the rate of change as a measure of velocity. This presupposes that students understand the relation between velocity and distance traveled. However, this relationship is taught in physics education with the use of graphs and the rate of change. In the next section we will argue that an overestimation of the explanatory power of graphs may be the cause of problems with the learning of these topics for students. We will suggest an approach of modeling motion which involves the students developing situation specific reasoning into reasoning with more formal and general mathematical ideas.

We designed an instructional sequence and two computer minitools for the teaching and learning of calculus and kinematics with help of the so-called emergent modeling design heuristic. Next, we created an educational setting with which we could understand and improve the intended learning processes and the means to support them. A research approach that consists of planning and creating innovative educational settings for analyzing teaching and 
learning processes is design research. The instructional sequence was investigated according to a design research approach in two tenth-grade classes. The interpretative framework for the teaching experiments was primarily an instructional design perspective inspired by realistic mathematics education. The conjectured process of teaching and learning guided the design decisions and framed the data analyses.

We analyzed the role of the teacher and of the computer tools in the observed teaching and learning processes. The aim of this research is a specification of the theory of realistic mathematics education into an instruction theory for our topic. The main research question is: how can students develop basic principles of calculus and kinematics in a process that evolves from situation specific reasoning to reasoning with general concepts?

\section{The didactical problem}

For many years, research shows that students who have followed calculus and physics classes have problems with interpreting graphical situations. In an extensive descriptive study, McDermott et al., (1987) identified difficulties that students have in making connections between kinematical concepts, their graphical representations, and the motion of real objects. A frequently recurring issue with graphs that describe motion is that they are interpreted as if they represent the actual trajectory of the moving object (McDermott et al., 1987; Clement, 1985; Monk, 2003). Global shapes of the graph are connected with visual characteristics of the situation (e.g., a bump in a distancetime graph is associated with a hill in the trajectory), and local characteristics of the situation are associated with corresponding characteristics of the graph. An illustrative example is that students interpret points of intersection in time-velocity graphs as moments where the one overtakes the other.

In many calculus and kinematics courses, a lot of attention is paid to how to perform calculations and algebraic manipulations, instead of attention to why they work (Clement, 1985; Dall'Alba et al., 1993). Students are usually not involved in the building of the models, their purposes, conventions, representations and their meanings in terms of the situations that are represented, and the kind of problems that can be solved. Education focuses on seemingly straightforward calculations, while the concepts are graphical and not trivial. This may be one of the causes of the above mentioned student problems.

As an alternative we want to involve students in the construction of the graphical models and the related ways of reasoning in order to prevent the above mentioned problems. In the following we will argue that open modeling activities are important for such an approach, because they show the students' reasoning and representational abilities that you can proceed from (Lesh et al., 2000).

Next, a learning trajectory is presented, that is used to investigate how students can participate in a learning process, in which the intended models are built. The idea is that students get opportunities to invent representations and meanings while they are guided by the teacher and by carefully introduced models. This process aims at the development of concepts which are rooted in the students' common sense reasoning.

\section{Theoretical framework}

Continuous velocity-time and distance-time graphs are models of situations that afford mathematical analyses of these situations. Their appearance and conventions (e.g., time-axis horizontal instead of vertical) are the result of a long history of scientific work on the calculus of change. During that era-prior to the development of continuous graphs-other models were developed and used for different purposes. After a period of almost 2000 years the graphs that we use nowadays were invented (e.g., Clagett, 1959). Continuous time graphs have become models that are used for reasoning about motion, time, distance traveled, velocity, and acceleration. Our claim is that a reinvention process of motion graphs will support students in developing their understanding of and mathematical reasoning with these graphs.

We investigated an approach that aims at a process in which the mathematics stays related to the students' understanding of the physical properties of motion, and emerges from their modeling activities. This is also in line with the objective of realistic mathematics education (RME), where instructional design aims at fostering the emergence of formal mathematical knowledge. During this process students can preserve the connection between the mathematical concepts and what is described by these concepts. Students' final understanding of the formal mathematics should stay connected with their understanding of these experientially real, everyday-life phenomena (Freudenthal, 1991).

The core mathematical activity of RME is mathematizing, which stands for organizing from a mathematical perspective. Freudenthal sees this activity of the students as a way to reinvent mathematics. However, students are not expected to reinvent everything by themselves. In relation to this, Freudenthal (1991) speaks of guided reinvention; the emphasis is on the characteristics of the learning process rather than on the invention as such. The idea is to allow learners to come to regard the knowledge they 
acquire as their own private knowledge, knowledge for which they themselves are responsible.

In a reinvention approach, the problem situations play a key role. Well-chosen context problems offer students opportunities to develop informal, highly context-specific models and solving strategies (Doorman et al., 2007). These informal solving procedures then may become subject of formalization and generalization to constitute a process of further abstraction, in RME dubbed as: progressive mathematization. The instructional designer tries to construct a set of problems that foster learning processes that result in the reinvention of the intended mathematics.

Research on the design of primary-school RME sequences has shown that emergent modeling can function as a powerful design heuristic (Gravemeijer, 1999). As a first step, the students are involved in modeling context problems that allow for situation-specific strategies, which may be modeled in an informal manner. Next the students are supported in developing both the model, and the related mathematical knowledge and understanding. The model develops in the sense that both the actual representation, and its meaning change. Even if the model is not actually invented by the students, great care is taken to approximate students' inventions as closely as possible by choosing models that link up with their current reasoning. Another important criterion is in the potential of the models to support mathematization towards the intended concepts. The idea is to look for models that can develop into entities of their own, which then can become models for mathematical reasoning (e.g., Gravemeijer \& Doorman, 1999; Gravemeijer, 2004; Rasmussen and Blumenfeld, 2007).

The shift from models of realistic situations to models for mathematical reasoning concurs with a shift in the way the student thinks about the model, from models that derive their meaning from the modeled context situation, to thinking about mathematical relations. In this context the term 'model' must be understood in a broad sense. It is not just the physical representation, but everything that comes with it (e.g., activity and purpose) that constitutes the model (Cobb, 1999). The underlying idea is that during students' activities the model and the situation being modeled co-evolve. Modeling in this view is a process of reorganizing both activities and situations. The situation comes to be structured in terms of mathematical concepts and relationships.

An additional theoretical foundation of the research we discuss here concerns the role of computer minitools in mathematics education. In general, tools influence the process of students' mathematical sense making. Cobb (1999) illustrated this by describing the interplay between students' ways of symbolizing and mathematical reasoning. In relation to this he analyzed how computer minitools afforded the students' reasoning on statistical problems
(Cobb, ibid). However, he argues, affordances are not properties of tools that exist independently of users, but are achievements of users in activity. As a consequence, instructional designers should take into account how students might act and reason with the tools as they participate in a sequence of mathematical practices.

We adopted these ideas for integrating two computer minitools in the instructional materials for the teaching and learning of calculus and kinematics. The tools enable students to trace subsequent positions of a moving object and to picture displacements and total distances traveled in two-dimensional graphs. We conjectured that the tools would support students in organizing motion with graphs, in finding patterns, and in developing physical and mathematical concepts related to motion and change.

This use of computer tools differs from instructional approaches in which the software offers dynamic linkages between simulations and continuous time graphs of motion. The primary goal of the latter approaches is that students discover the meaning of the external representations on the computer screen while exploring these dynamic linkages (Doerr, 1997). The difference between the two approaches has many similarities with the distinction between designing models in co-construction and providing models for exploration (Van Dijk et al., 2003).

Finally, research into the use of hand-held calculators and computer tools also points at the importance of the teacher's role. The process of tool appropriation and learning mathematics has both an individual and a collective aspect, and needs guidance by the teacher (e.g., Doerr $\&$ Zangor, 2000). We used the design heuristic of problem posing (Klaassen, 1995) to support the teacher in guiding the students. The problem posing heuristic gives suggestions to the teacher on how to foster content-related motives for the way to proceed with the lessons by having the students come up with questions that still have to be solved. The content-specific motives are supported by an overarching problem for all consecutive lessons which relates to the successive activities.

The goal of our research was to investigate how students can reinvent the basic principles of change and velocity in a process of teaching and learning from situation specific reasoning towards general concepts. We conjectured that the design heuristics of emergent modeling, of tool-use and of problem posing have the potential for realizing this process.

\section{Methods}

The aim of this research is to investigate a learning process in the domain of calculus and kinematics that progressively builds on students' inventions, and the means of supporting 
and organizing that process. To achieve this, we created an educational setting in which we could investigate to what extent and how this dialectic process of symbolizing and meaning making could be fostered. We designed an instructional sequence for creating this setting and being able to analyze teaching and learning processes in teaching experiments. This educational research method is characterized as design research and consists of planning and creating innovative educational settings for investigating teaching and learning processes.

This interpretation of design research has proved itself suitable for developing empirically grounded instruction theories in the areas of science and mathematics education (Gravemeijer, 2004; Lijnse, 1995). The approach aims at generating empirically grounded theories. The main result is not primarily a design that works, but the rationales of how it works (Cobb et al., 2003; Edelson, 2002; Gravemeijer \& Cobb, 2006).

A literature review on the history of calculus and on recent teaching experiments within this domain resulted in initial conjectures for the learning of calculus and kinematics and the means to support this learning (Gravemeijer \& Doorman, 1999). These means of support consist of a sequence of activities for the students, computer tools, and actions of the teacher. In addition to the design of this instructional sequence (see next section) we formulated testable conjectures and observation criteria. These conjectures concerned the major shifts in students' reasoning in relation to the means of supporting and organizing those shifts. The sequence and the related conjectures constitute a conjectured local instruction theory (Gravemeijer, 2004). Such a conjectured theory encompasses possible scenarios of the lessons and a justification of the choices made. It has much in common with a hypothetical learning trajectory (Simon, 1995), and is used as a guidance for the data analysis.

The first teaching experiment took place in two 10th grade classes in two secondary schools in provincial towns. For the first experiment we collected data from various sources to be able to cross check assumptions that might emerge from one data source. The student activities, the guidelines for the teacher, and our intentions, were discussed beforehand with the teachers of both schools in two meetings. During the experiments we made field notes and audio-taped the lessons. The observer participated in the discussions between the students to ask for clarification of their reasoning. During the computer lessons, one pair of students was video-taped, and whole-classroom discussions were also video-taped. The pair was selected with help from the teachers using the criteria of clear speech and average capabilities.

We used the video-tapes to analyze gestures and reasoning with graphs on the computer screen and on the blackboard. After the teaching experiments we collected the students' written materials and results on an achievement test. The data was used to analyze the learning process, and to investigate to what extent we had reached content-specific goals.

Initially, the data-analysis aimed at understanding the learning process of the students. This analysis also provided information on how to improve the activities with respect to formulating student texts, contexts used, and information provided. For example, some students appeared to have difficulties with interpreting and using the graphs provided by the tools. This led to adjustments to the sequence and to a new conjecture for a second experiment. We conjectured that whole class discussions about the use of specific graphs would prepare all students for the computer lessons. As a result of this, we looked for ways to support such whole class discussions for reaching consensus in the classroom about a way to proceed with the computer tools. The adjustments and the new conjectures were objects of study in the second teaching experiment.

The second teaching experiment was confined to eight lessons in one 10th grade classroom. During these lessons we focused our data collection on the instructional activities and the computer tools. We assumed that one classroom experiment would provide us with enough data for qualitative analyses of the teaching and learning processes. This experiment took place in a secondary city school with a teacher who was experienced in discussing mathematical problems with students without presenting them with the intended approach or answer. We discussed with the teacher the planning of the activities and especially the scope of the classroom discussions.

For analyzing the development in reasoning with the computer tools we audio-taped one pair, and video-taped another pair during the computer activities. Classroom discussions were video-taped and field notes and student work were assembled just as in the first teaching experiment. In these experiments we expected to collect enough information to analyze the classroom process of the teaching and learning of calculus and kinematics.

The data were organized and elaborated into case studies of class discussions and of students' work during the computer lessons. The interpretative framework for the teaching experiments was primarily that of socio-constructivism and RME theory. We interpreted the case studies with the conjectured local instruction theory in terms of what preceded the lessons, the student activities, the teaching, and the tools provided. In this first round of analysis, we developed conjectures about the students' thinking, which we tested on all data in a second round of analysis. In addition, we tried to assign such meanings to students' expressions that they came out as consistent with their history and the current classroom situation. (For a more detailed discussion of the methodology and 
the validity of these instruments, see Doorman, 2005.) The result of this analysis is presented in Sect. 6, in the form of a report of what happened during the teaching experiments.

\section{The instructional design}

The literature review on the history of calculus and recent teaching experiments pointed us towards the importance of starting with discrete graphs (Boyd \& Rubin, 1996; Gravemeijer \& Doorman, 1999). We designed an instructional sequence in which discrete graphs would start as models of motion of a hurricane, and develop into models for reasoning about the relation between displacements in time intervals and total distance traveled. Weather forecasting, especially the change of position of hurricanes, seems to be a situation that lends itself for modeling motion. The question is: when will the hurricane reach land? This problem is posed as a leading question throughout the unit as a context for the need of grasping change (see Fig. 1).

After being introduced to time series, students work with situations that are described with stroboscopic photographs. The idea is that students come up with measurements of displacements as basic structuring elements of motion that may be displayed graphically in a natural manner (based upon Boyd \& Rubin 1996). The key issue that should arise in the discussion is how to describe change (of position) in order to discern patterns and to be able to make predictions.

The introductory part of the instructional sequence comprised one lesson. Describing and predicting change were introduced in the context of weather forecast. The central question for the students was: how can you describe change in order to make predictions?

A representation of a time series is a trace graph of points and connecting lines (see Fig. 1). This representation in the weather context is the starting point for understanding the importance of gaining insight into patterns of trace graphs for making predictions. The classroom discussion based on students' reasoning should result in a consensus on proceeding with two-dimensional displacement graphs and total distance-traveled graphs. To achieve the transition from trace graphs to reasoning with twodimensional graphs of motion, we designed an open modeling activity about a falling ball (given: a stroboscopic picture of a falling ball; question: design a representation to predict when it will hit the ground). We expected that the teacher could use the strategies of the students to reveal
Fig. 1 A tropical storm approaching the coast

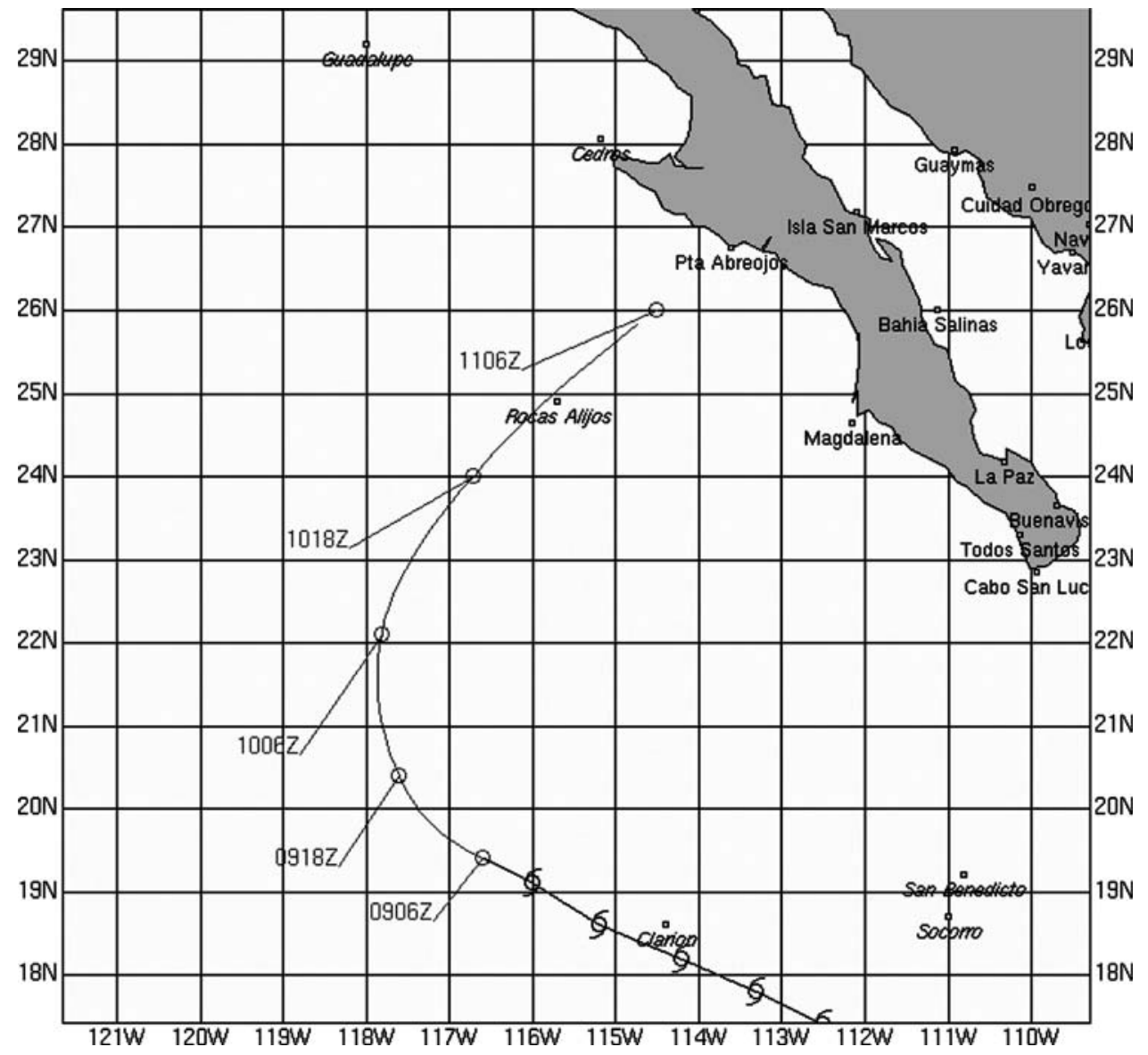


their current reasoning, and use their graphs to introduce the graphs in the computer tool. This activity was to be followed by the computer lesson.

In the computer activities we gave students the opportunity to investigate various situations with the computer program Flash. We wanted them to construct relations between patterns in trace graphs and graphical characteristics during their investigations. More specifically, the use of the computer tool should enable the students to construe properties like the relation between average displacement and total distance traveled, and to find the relation between the linearity of a distance traveled graph for a motion with constant displacements.

For instance, the students could click on successive positions of an object in a stroboscopic picture. Simultaneously, the program shows the distances between these positions in a table, and displays them in a displacement graph or in a graph of total distances. The values are displayed as vertical bars instead of dots to preserve the link with the displayed measurements and as a preparation for reasoning with intervals - as basic structuring elementsin continuous graphs (see Fig. 2).

The clicking of successive positions signified measuring displacements in successive time-intervals. Activities for the students consisted of various situations in which they could click on successive positions and could reason with the table, with the two graphs for solving the problem stated (e.g., "when will the hurricane hit the coast?"), and with a continuation of the last displacement (as in Fig. 2).
Initially, these graphs are used to describe the situations and are related to measurements in the pictured situation. Gradually, the attention is shifted towards graphical and conceptual relations between displacements and distances traveled (e.g., "a horizontal line of summit in the displacement graph signifies a constant velocity"). What used to be a record of measurements is now used as a tool for reasoning about time and relations between velocity and distance. This implies a shift in the way the students think about the graphical model, from a model that derives its meaning from the modeled context situation, to a model that signifies mathematical relations.

Note that a key element of the emergent modeling design heuristic is that the models first come to the fore as models of situations that are experientially real for the students. The underlying idea is that discrete graphs are not introduced as an arbitrary symbol system, but as consecutive models of discrete approximations of a motion that link up with prior activities and students' current reasoning (see Fig. 3).

We expected that during the computer activities students would work at a different pace. Therefore, afterwards we added an activity to review the technical skills for drawing graphs, and to reflect upon developed language, concepts and graphs. This reflection is supposed to take place in the class discussion based on the students' solutions of describing the motion of a bungee jumper.

As a next step, the notion of instantaneous speed is introduced in the context of a narrative about Galileo's work. In this context instantaneous velocity is needed to be
Fig. 2 Modeling the motion of a storm with Flash
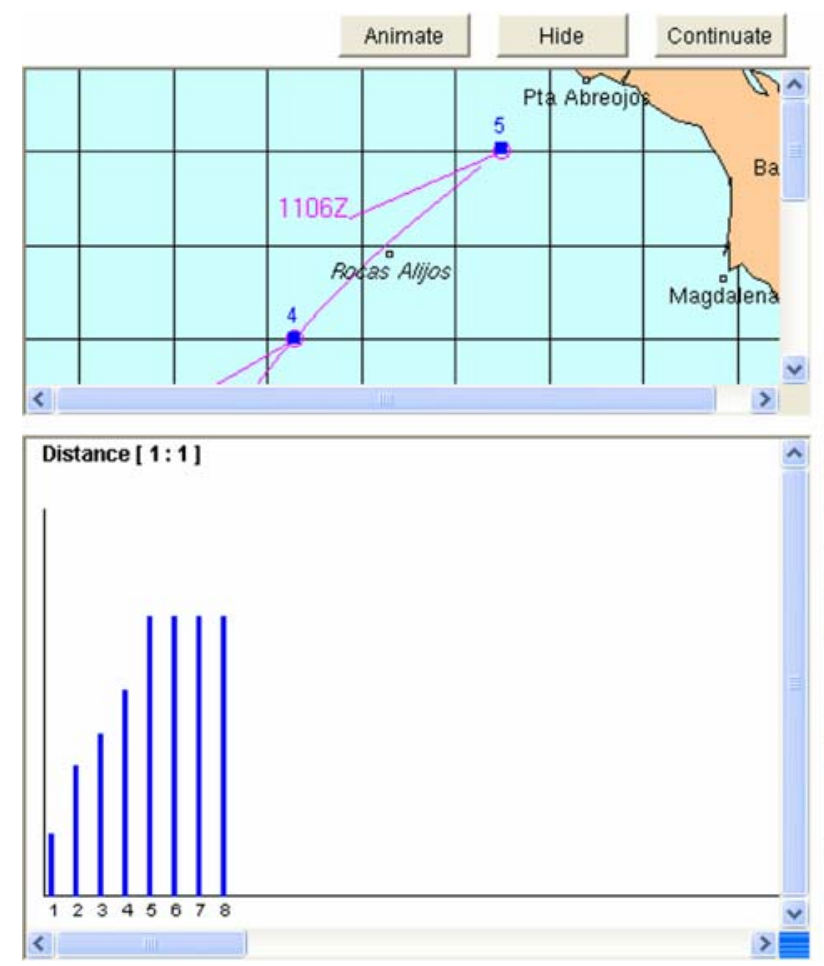

\begin{tabular}{|l|l|l|}
\hline Stretch & Blue & Red \\
\hline \multirow{3}{*}{$0-1$} & $9 \mathrm{~mm}$ & \\
\cline { 2 - 3 } $1-2$ & $19 \mathrm{~mm}$ & \\
\cline { 2 - 3 } $2-3$ & $24 \mathrm{~mm}$ & \\
\cline { 2 - 3 } $3-4$ & $30 \mathrm{~mm}$ & \\
\cline { 2 - 3 } $4-5$ & $42 \mathrm{~mm}$ & \\
\cline { 2 - 3 } $5-6$ & $42 \mathrm{~mm}$ & \\
\cline { 2 - 3 } $6-7$ & $42 \mathrm{~mm}$ & \\
$7-8$ & $42 \mathrm{~mm}$ & \\
\cline { 2 - 3 } & & \\
0
\end{tabular}

Selected table

Blue selected $\checkmark$

Visible table

V Blue

V Red

View

Displacements

Scale of vertical axis

$1: 1$ 


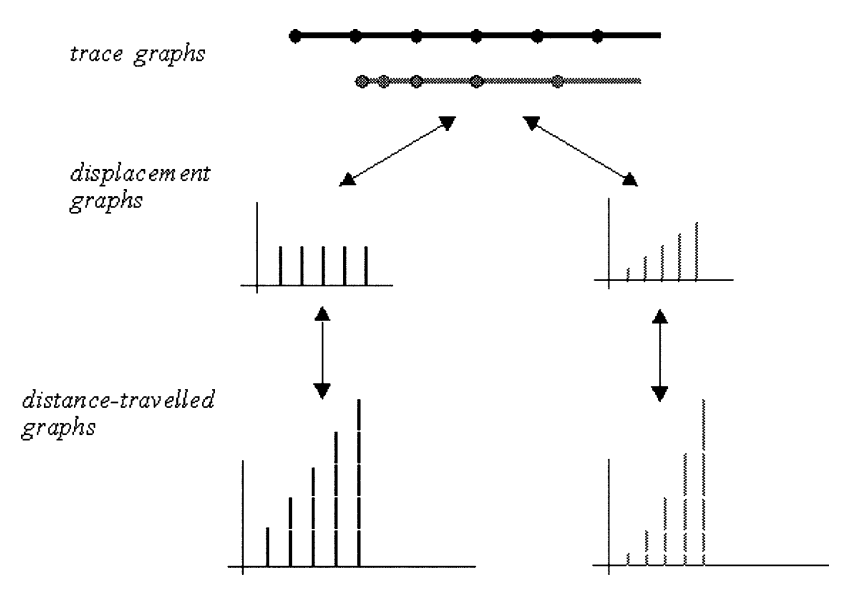

Fig. 3 Consecutive manifestations of a model of motion

more precise in predicting falling distance and falling speed when you have formulas of motion at hand. Instantaneous velocity is defined in accordance with the medieval notion, in terms of the distance that would be covered if the moving object would maintain its instantaneous velocity for a given period of time. The problem is posed of how to verify Galileo's hypothesis on free fall: velocity increases constantly, and is proportional to time. Figuring this out demands of the students that they come to grips with the relationship between the motion, the representations, and the approximation (Roth \& Tobin, 1997). During this process, the way of modeling motion and the conceptualization of the motion that is being modeled, co-evolve. Reasoning with the basic structuring elements-horizontal and vertical intervals-refers to the activities with the discrete graphs and play a key role in this shift.

Finally the attention shifts from problems cast in terms of everyday-life contexts to a focus on the mathematical and physical concepts. In order to enable the students to make such a shift, they have to develop a mathematical framework of reference that enables them to look at these types of problems mathematically (see also Simon 1995). In this framework students are supposed to understand that change of a function can be displayed by graphing differences between successive values (displacements in our example), and that a specific function value (the total distance traveled) can be found by adding a series of differences. The relation between taking differences and adding up frames the main theorem of calculus. It is exactly the emergence of such a framework of graphical relationships that this sequence tries to foster. It is this framework that enables the students to trace the origin of the mathematical models and to anticipate on what is to come.

\section{Teaching experiments}

The conjectured instruction theory was elaborated in an instructional sequence of ten lessons including two computer lessons. This sequence was investigated in two teaching experiments.

The first teaching experiment started as planned. As a result of the character of the introductory class discussion we noticed that the importance of a graphical description for making predictions had started to become clear to the students. Students contributed to the idea that time series play a key role in this process. With the contributions of the students, consensus was established about the model of the time series: the trace graph. In their reasoning, changes in velocity signified changes in lengths of displacements in subsequent time intervals.

However, during the whole class discussion about the introductory activities the teachers did not focus on the patterns in displacements as a problem for predicting weather. These patterns should have resulted in a motive for the two-dimensional graphs. We concluded that during this lesson the patterns in displacements and the use of twodimensional graphs were not successfully addressed. In the second teaching experiment we improved this lesson. We could better discuss the purpose of the activities with the teacher and we added a model eliciting activity about a stroboscopic picture of a falling ball to focus on the pattern.

As a result of the open-ended activity before the computer lesson, the students had a means available for modeling motion with two-dimensional discrete graphs and their possibilities for predictions. During the activity about a pattern in the displacements of the falling ball, we saw the diversity of solutions we had hoped for. Students identified different variables for their graphs (height, displacement, distance traveled, time, number of flashes), and most of them drew a line of summit through the dots (see Fig. 4).

The teacher asked the students to show their solutions and organized a whole class discussion about differences and similarities in the solutions. Many students were involved and the classroom community seemed to reach a consensus about the possibilities and usefulness of twodimensional discrete graphs (with displacements and with total distance traveled) as tools for describing and predicting motion. This proved to be a productive preparation for the computer lesson with the computer program Flash.

The aim of the second lesson, a computer lesson, was that students should begin to understand the need to display patterns and to understand the relation between these patterns and the characteristics of displacement graphs and distance-traveled graphs. The measuring by clicking and the construction of graphs did focus the students on change in displacements and reasoning with the Flash-graphs.

At the beginning of the computer activities, the students' language primarily referred to successive positions in the stroboscopic photograph. They used thumb and index finger to visually transfer lengths of bars in the graph to displacements in the stroboscopic picture. As the lesson 
Fig. 4 Three graphs by students describing free fall
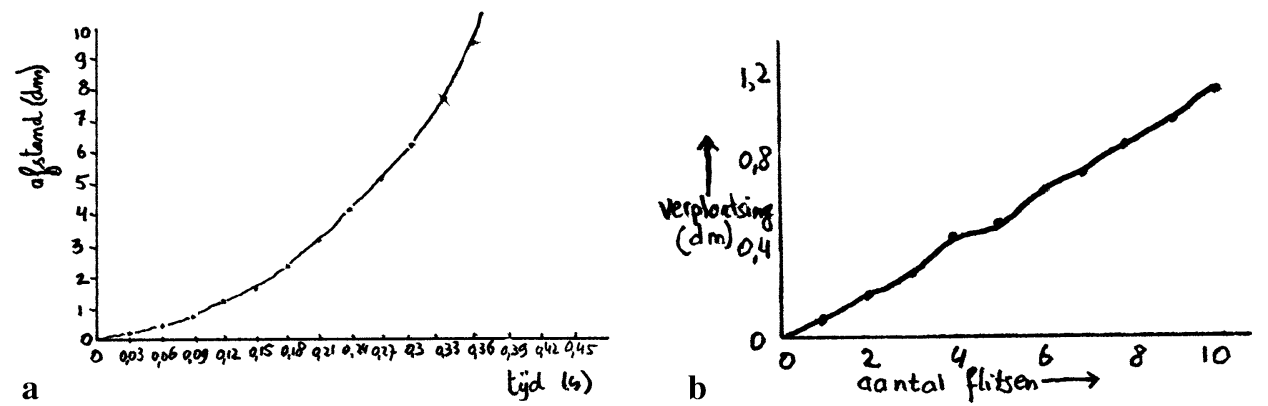

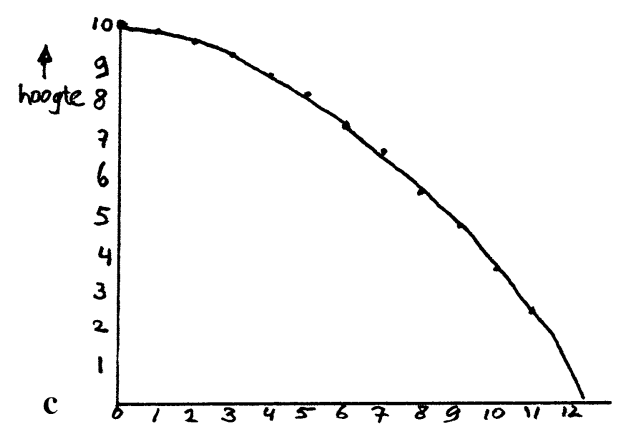

progressed, their discussions increasingly involved characteristics of the graphs of displacements and of total distances traveled. The students started to grasp the relation between a graph of constant displacements and the accompanying 'linear' graph of total distance traveled.

During ensuing problems students increasingly used the change of the displacements in the graph to describe motions and to make predictions. Through the use of Flash their attention during the activities became focused on properties of graphs. Sometimes they still referred to distances between the dots in the photograph, but more and more they reasoned with the global shapes and properties of the two discrete graphs. The following vignette illustrates this reasoning by the students ( $\mathrm{J}$ and $\mathrm{M}$ ). The students work on an exercise about a zebra which is running at a constant speed and a cheetah that starts hunting the zebra. In the introduction of the activity it is said that the students have to disregard some of the aspects in the situation (both animals are supposed to follow the same path). The discussion took place as a result of the question of whether the cheetah would catch the zebra (see Fig. 5). The observer (O) participates.

M: $\quad$ Yes, the cheetah would still catch up

O: Really? How did you conclude that?

M: Uhm, then you put two here together and then you can see here that they're both equal

O: $\quad$ Yes. And which of the two graphs is that?

$\mathrm{J}+\mathrm{M}$ : That's the total distance traveled [they point at the left graph below]

O: Oh yes. So why did you choose the one for the total distance?

J: $\quad$ Because it's the total distance that they cover and then you can.
M: Then you can see if they catch up with each other

O: $\quad$ And cannot you see that in the other? There you can also see that the red catches up with blue? [He points at measurement 3 in the right graph.] J: $\quad$ Yes, but ...

M: $\quad$ Yes, but that's at one moment. That only means that it's going faster at that moment but not that it'll catch up with the zebra.

The vignette illustrates that the two students understood the difference between the distance traveled and the displacement graph. When both distance traveled graphs are 'equal' (i.e., have the same height), both animals have traveled the same distance. In addition, they could clarify the different meaning of the crossing of the line of summit in the displacement graphs.

An important difference between the displacements graph and the distance-traveled graph is the difference in interpretation of the horizontal (time) axis. A value in the distance-traveled graph (i.e., the height of a bar) represents a distance from the start until the corresponding time, while a value in the displacements graph represents a distance in the corresponding time interval. The final observation of the students is an important step in the process of building the model of a velocity-time graph (and everything that comes with it).

During the computer lesson, the majority of the students increasingly reasoned about the characteristics of, and relation between, the two discrete graphs and their meaning for the specific situations. After this lesson, the teacher started a discussion about their experiences based upon an extra small group activity where they had to describe the 
Fig. 5 Graphs of a cheetah chasing a zebra

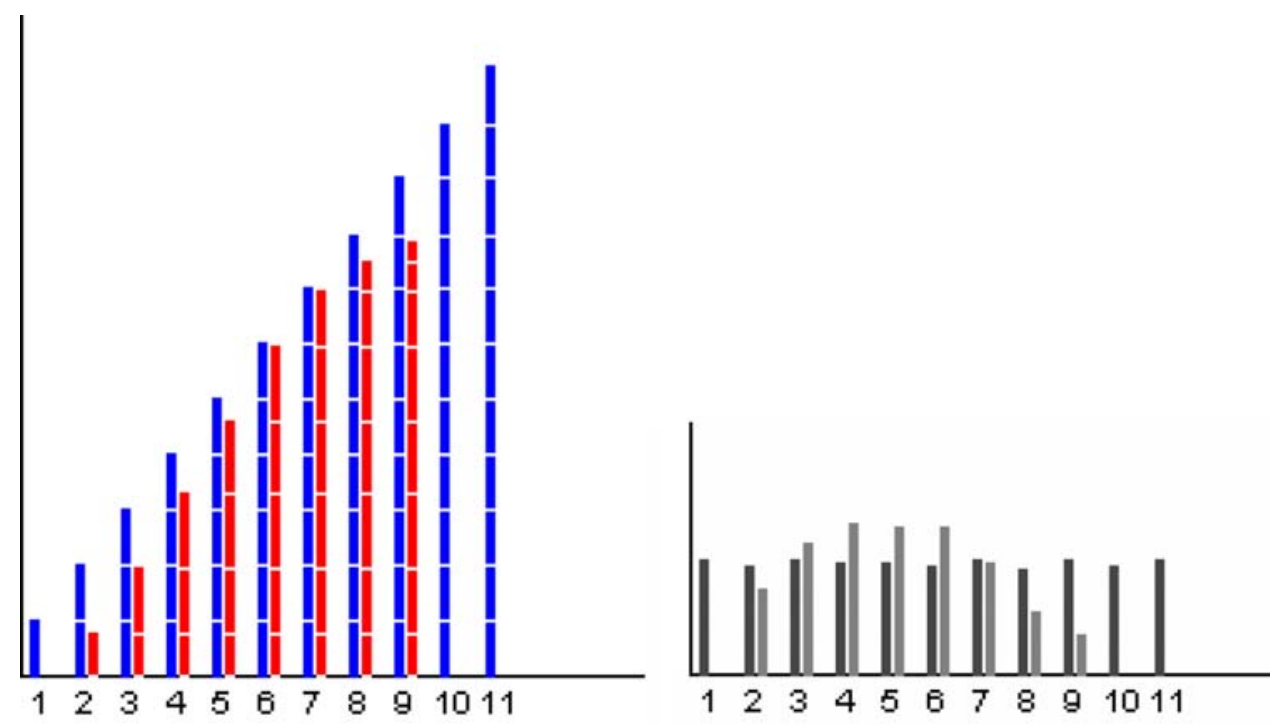

motion of a bungee jumper without the aid of the computer. The students' reasoning created opportunities for the teacher to frame topics for discussions on general relationships between graphs of displacements and of total distances traveled. Many students participated actively in this discussion. In the next vignette two students $(\mathrm{N}$ and $\mathrm{M})$ present their graph to the class and the teacher (T).

$\mathrm{N}$ : Well then, this is the distance traveled and that means that the bungee jumper goes down here and therefore he goes faster, because he travels a greater distance in a shorter time. And here he goes down again: And then he travels a smaller distance in the same time and then he goes back up and back down again... [tracing the distance traveled graph, which doesn't go down but has alternating large and small slopes]

$\mathrm{T}$ : May I make a very small addition to interpret what you are saying, because you're all saying it very well, only what you're also saying is that you can see how fast he's going by looking at how steep that thing is [pointing at the distance traveled graph]. Or not?

$\mathrm{N}$ : Yes

T: Can you explain that a bit better?

(...)

$\mathrm{N}$ : Well, because in this little piece of time [she points at an accompanying increase in the displacementgraph], he travels quite a long distance [points finger up and down along the displacement]. While in this one here it takes him longer to go the same distance [she moves her finger along a less steep part of the distance traveled graph]

M: In the same time....

During all presentations, the teacher acted in a similar manner as in this vignette, by asking the students to use characteristics of the motion while talking about the graphs, by making occasional references to experiences with Flash. Students pointed to graphical characteristics during their presentations, and used the displacements as a measure for velocity in connection with the total distance traveled. Based on this activity, a class consensus was achieved about the interpretation of, and the connection between the discrete graphs. This connection can be seen as a crude version of the main theorem of calculus that would be addressed in the final lessons of the sequence.

In the subsequent lessons the displacements were scaled to a compound dimension for velocity. The attention in the activities and the whole class discussions shifted to continuous time-graphs and to reasoning with intervals for calculating average velocity and approximating instantaneous velocity.

On the final achievement test the students successfully interpreted of the difference quotient as a measure for change, although there were some difficulties with the use of dimensions in this process. When asked to determine an instantaneous velocity with a given distance-time graph, most students (21 out of 33) used a small interval to solve the problem and 5 initially drew a tangent. The remaining students (6) did not answer the question successfully.

In an item about the growth of a sunflower, the students had to estimate the average growth speed during three consecutive specific days. Almost all students interpreted the difference quotient correctly. A characteristic answer was: $\Delta y / \Delta x=100 \mathrm{~cm} / 3$ days $=33.3 \mathrm{~cm}$ per day.

One test item had a question about the difference between instantaneous and average velocity. Most students' answered this adequately. One answer is shown below; it was more detailed than the answers of the majority of the students but illustrates their way of reasoning: 
"The average velocity is how fast you go, for example, during several minutes. If you, for example, go $1,000 \mathrm{~m}$ in $5 \mathrm{~min}$, your average velocity during this period is $1,000 / 5=200 \mathrm{~m} / \mathrm{min}$. But that does not mean that you are going at a constant velocity of $200 \mathrm{~m} / \mathrm{min}$. For example, you might start slowly and then go faster and faster, or you might begin fast and then slow down. The instantaneous velocity is the velocity at a specific instant, for example, that you are going at $100 \mathrm{~m} / \mathrm{min}$ after $1 \mathrm{~min}$. So the instantaneous velocity is exactly how fast you are going at one instant, which therefore has nothing to do with the average. An average is your velocity taken over a certain period."

Other students referred to characteristics of the $s-t$ graph (on a linear distance traveled graph the instantaneous velocity equals average velocity) or to the accompanying calculations $(\Delta s / \Delta t$ with a very small $\Delta t$ for an instantaneous velocity).

We concluded from these results that most students showed the ability to reason with change and with graphs of motion by using horizontal and vertical intervals, their quotients and their dimensions.

\section{The emerging instruction theory}

Analysis of the actual process of teaching and learning provides information that can be used to guide revisions of the instructional activities and to specify the rationale that underpins the theory. The cyclic process of thought experiments and teaching experiments forms the backbone of the design research method for developing empirically grounded instruction theories.

The empirical data were interpreted in light of the hypothetical learning trajectory and the specific design heuristics. We conjectured that activities with computer tools need careful preparation beforehand, and reflection afterwards. The open modeling activity before the Flash lesson supported the students' inventions of, and reasoning with, graphs. The variety in solutions enabled the teacher to make graphical models of motion a topic of discussion for the students and to help them to reach consensus about the way to proceed. Their understanding of the graphs provided by the tool was an important condition for their meaningful and flexible reasoning with the tool. We observed the changing language of the students with increasing references to characteristics of and relations between the two discrete graphs while describing motion.

In this paper we focused on the way discrete graphs could support the development of the basic principles of calculus and kinematics. The emerging-empirically supported- instruction theory is a reconstruction of a sequence and its rationale that underpins it, and that builds on what is seen as the successful elements of the teaching and learning process. The relation between the discrete graphs, the intended activities and conceptual development of the students can be summarized as a chain of signification in a table (see Table 1). In previous design research such a table proved useful for describing a local instruction theory on measurement and flexible arithmetic (Gravemeijer, 2004).

The first column of this table is labeled 'tool' to emphasize the tool-character of the inscriptions. The 'imagery' column refers to the history that frames students' perception. By providing this column we show how the tool derives its meaning from situational (predicting the weather with trace graphs), via referential (discrete two-dimensional graphs of displacements and distances traveled) to general (reasoning with difference quotient and slope and area in continuous graphs of velocity and of distance traveled). The activities and discussions that address specific concepts should result in motives to proceed. In our approach we focused especially on establishing these motives, and we have therefore added them to the table.

The table gives an overview of (1) how students are expected to act and reason with the tools, (2) how an activity relates to preceding activities, and (3) the conceptual development aimed at by that activity.

\section{Discussion}

In the classroom learning process, we noticed that students initially reasoned and wrote about mathematical and kinematical notions with a tentative language and inscriptions that were not as precise as the notions aimed at. This process from situational and tentative to general reasoning seems similar to Goldin's description of three main stages in the development of representational systems: (1) an inventive and semiotic stage, (2) structural development and establishment of relationships, and (3) an autonomous stage (Goldin, 2003). During the inventive stage, students tentatively used inscriptions and language to communicate their developing ideas. In the autonomous stage the system can function flexibly in new contexts. We observed that the teacher played an important role during this process. The teacher guided whole class discussions and alternated between stimulating students to present their solutions and focusing to the mathematics needed for what is to come (Sherin, 2002). Open modeling activities (e.g., the falling ball and the bungee jumper) created opportunities for the teacher to guide these whole class discussions.

In RME approaches, the final model is the result of modeling activities in which students' constructions play a central role. The related inscriptions and language are 
Table 1 Summary of an emerging instruction theory

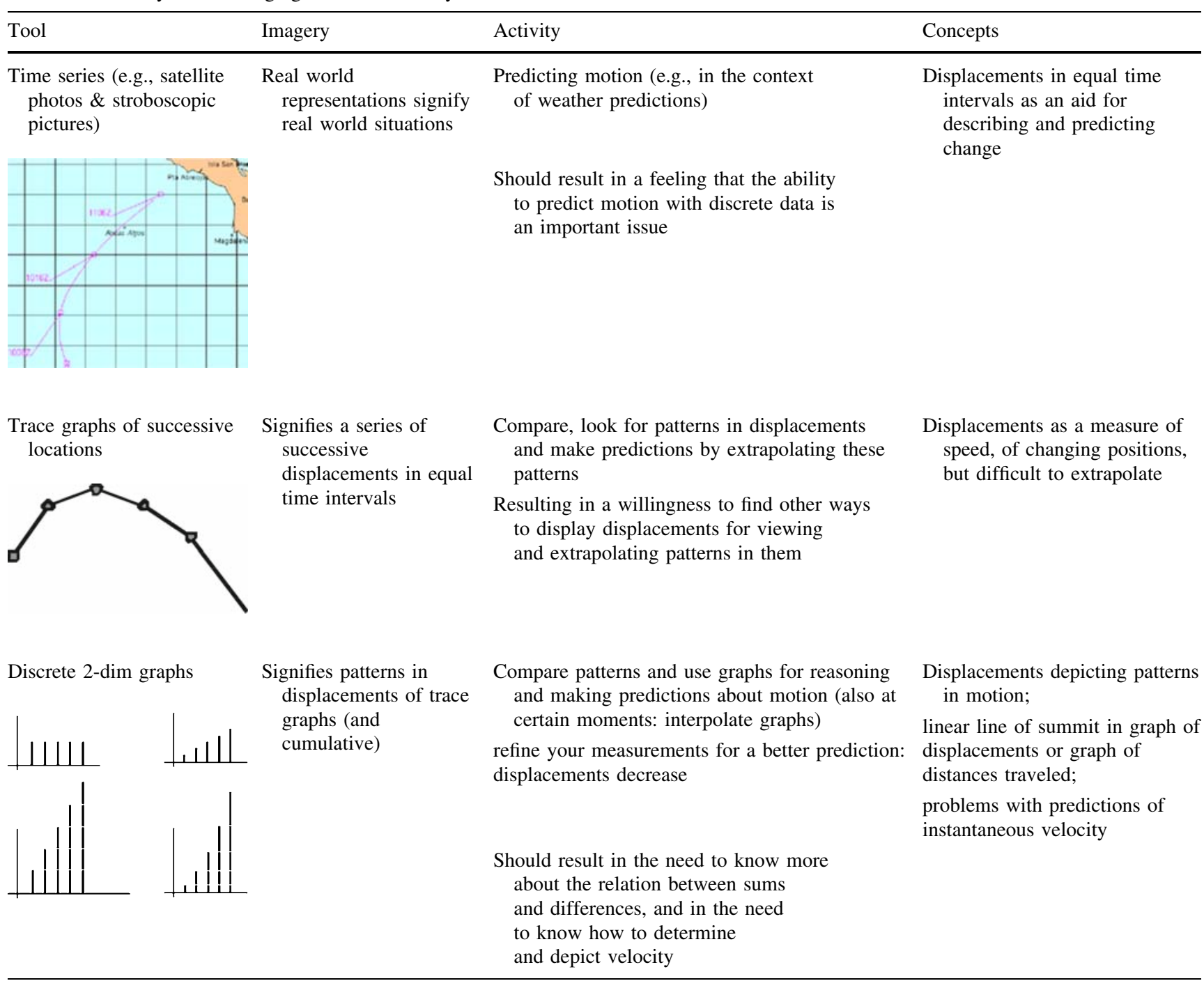

progressively developed from situational to general through these activities. Tool-use and carefully introduced models support and link up with students' inventions. It is difficult_maybe even impossible-to design learning processes for classroom situations in which all students experience their learning process as invention. However, a learning trajectory that supports invention and which makes it possible to trace meaning through a series of inscriptions that build progressively on each other provides the teacher with possibilities for guiding the students' reasoning. This can be realized when the consecutive models as well as the tools in the software are part of an emergent modeling process and are-as much as possible-compatible with the students' current reasoning. The focus on the alignment of the activities sometimes has as a consequence that not all aspects of the modeling are critically addressed (e.g., the case of the cheetah hunting the zebra).

The design heuristic of emergent modeling assigns a role to models that differs from the traditional didactical role of models in mathematics education: instead of trying to concretize abstract mathematical knowledge, the objective is to try to help students model their own informal mathematical activity.

The label 'emergent' refers both to the character of the process by which models emerge within realistic mathematics education, and to the process by which these models support the emergence of formal mathematical ways of knowing. From this perspective, the process of constructing discrete graphs is one of progressively reorganizing situations. The model and the situation being modeled coevolve and are mutually constituted in the course of 
modeling activity. Instead of thinking in terms of "cutting bonds with (everyday-life) reality", the construction of the mathematics of change stays in connection with situational knowledge (Gravemeijer, 2007). In this approach, modeling serves not only as an instructional goal but also as a means of supporting the reinvention of mathematics.

This research indicated that students' conceptual problems in applying mathematical notions in other topics can be prevented by starting the process of teaching and learning in the context of applications (e.g., Michelsen, 1998). However, we do not believe that all mathematical topics can be developed through such an integrated approach. Some topics are essentially the result of a process of organization within or between mathematical structures. In fact, the trajectory in this research should also be followed both by a series of lessons where the mathematics of change is developed as a generalizing principle for many applications, and by elaborating the topic within a mathematical context.

This study has provided some insight into the constraints and possibilities for the integration of physics and mathematics. We recommend further research for the understanding of the teaching and learning of science and mathematics as closely related disciplines, and for implementing real changes in the way these topics are covered in schools.

Acknowledgments The authors want to thank the reviewers for their critical and constructive comments. This research was funded by NWO, the Dutch National Science Foundation, under grant no. 57536-03C.

Open Access This article is distributed under the terms of the Creative Commons Attribution Noncommercial License which permits any noncommercial use, distribution, and reproduction in any medium, provided the original author(s) and source are credited.

\section{References}

Boyd, A., \& Rubin, A. (1996). Interactive video: A bridge between motion and math. International Journal of Computers for Mathematical Learning, 1, 57-93.

Clagett, M. (1959). Science of mechanics in the middle ages. Madison: The University of Wisconsin Press.

Clement, J. (1985). Misconceptions in graphing. In L. Streefland (Ed.), Proceedings of the Ninth International Conference for the Psychology of Mathematics Education, Utrecht: Utrecht University, pp. 369-375.

Cobb, P. (1999). Individual and collective mathematical development: The case of statistical data analysis. Mathematical Thinking and Learning, 1(1), 5-43.

Cobb, P., Confrey, J., diSessa, A. A., Lehrer, R., \& Schauble, L. (2003). Design experiments in educational research. Educational Researcher, 32, 9-13.

Dall'Alba, G., Walsh, E., Bowden, J., Martin, E., Masters, G., Ramsden, P., et al. (1993). Textbook treatment of students' understanding acceleration. Journal of Research in Science Teaching, 30(7), 621-635.

Doerr, H. M. (1997). Experiment, simulation and analysis: An integrated instructional approach to the concept of force. International Journal of Science Education, 19(3), 265-282.

Doerr, H. M., \& Zangor, R. (2000). Creating meaning for and with the graphing calculator. Educational Studies in Mathematics, 41, 143-163.

Doorman, M., Drijvers, P., Dekker, T., Van den Heuvel-Panhuizen, M., De Lange, J., \& Wijers, M. (2007). Problem solving as a challenge for mathematics education in The Netherlands. ZDM Mathematics Education, 39(5-6), 405-418.

Doorman, L. M. (2005). Modeling motion: From trace graphs to instantaneous change. Utrecht: CD-Beta Press.

Edelson, D. C. (2002). Design research: What we learn when we engage in design. The Journal of the Learning Sciences, 11(1), $105-121$.

Freudenthal, H. (1991). Revisiting mathematics education-China lectures. Dordrecht: Kluwer Academic Publishers.

Goldin, G. A. (2003). Representation in school mathematics: A unifying research perspective. In J. Kilpatrick, W. G. Martin, \& D. Schifter (Eds.), A research companion to Principles and Standards for School Mathematics. Reston: NCTM.

Gravemeijer, K., \& Cobb, P. (2006). Design research from the learning design perspective. In J. van den Akker, K. Gravemeijer, S. McKenney \& N. Nieveen (Eds.), Educational design research (pp. 17-51). London: Routledge.

Gravemeijer, K. P. E., \& Doorman, L. M. (1999). Context problems in realistic mathematics education: A calculus course as an example. Educational Studies in Mathematics, 39(1-3), $111-129$

Gravemeijer, K. (1999). How emergent models may foster the constitution of formal mathematics. Mathematical Thinking and Learning, 1(2), 155-177.

Gravemeijer, K. (2004). Local instruction theories as means of support for teachers in reform mathematics education. Mathematical Thinking and Learning, 6, 105-128.

Gravemeijer, K. (2007). Emergent modelling as a precursor to mathematical modelling. In W. Blum, P. L. Galbraith, H.-W. Henn, \& M. Niss (Eds.), Modelling and applications in mathematics education. The 14th ICMI Study (pp. 137-144). New York: Springer.

Klaassen, C. W. J. M. (1995). A problem-posing approach to teaching the topic of radioactivity. Utrecht: CD-Beta Press.

Lesh, R., Hoover, M., Hole, B., Kelly, A., \& Post, T. (2000). Principles for developing thought-revealing activities for students and teachers. In A. Kelly, \& R. Lesh (Eds.), Handbook of research design in mathematics and science education. Mahwah, NJ: Lawrence Erlbaum.

Lijnse, P. L. (1995). 'Developmental research' as a way to an empirically based 'didactic structure' of science. Science Education, 79, 189-199.

McDermott, L. C., Rosenquist, M. L., \& van Zee, E. H. (1987). Student difficulties in connecting graphs and physics: Examples from kinematics. American Journal of Physics, 55(6), 503-513.

Michelsen, C. (1998). Expanding context and domain: a crosscurricular activity in mathematics and physics. ZDM Mathematics Education, 30(4), 100-106.

Monk, S. (2003). Representation in School Mathematics: Learning to Graph and Graphing to Learn. In J. Kilpatrick et al. (Eds.), A research companion to principles and standards for school mathematics. Reston: NCTM.

Rasmussen, C., \& Blumenfeld, H. (2007). Reinventing solutions to systems of linear differential equations: A case of emergent models involving analytic expressions. Journal of Mathematical Behavior, 26, 195-210. 
Roth, W., \& Tobin, K. (1997). Cascades of inscriptions and the representation of nature: How numbers, tables, graphs, and money come to re-present a rolling ball. International Journal of Science Education, 19(9), 1075-1091.

Sherin, M. G. (2002). A balancing act: Developing a discourse community in a mathematics community. Journal of Mathematics Teachers Education, 5, 205-233.
Simon, M. A. (1995). Reconstructing mathematics pedagogy from a constructivist perspective. Journal for Research in Mathematics Education, 26(2), 114-145.

Van Dijk, I. M. A. W., Van Oers, B., \& Terwel, J. (2003). Providing or designing? Constructing models in primary maths education. Learning and Instruction, 13, 53-72. 